\title{
RAFT-based tri-component fluorescent glycopolymers: synthesis, characterization and application in lectin-mediated bacterial binding study
}

\author{
Wei Wang • Deborah L. Chance • Valeri V. Mossine • \\ Thomas P. Mawhinney
}

Received: 20 July 2013 /Revised: 30 September 2013 / Accepted: 28 October 2013 / Published online: 12 November 2013

(C) The Author(s) 2013. This article is published with open access at Springerlink.com

\begin{abstract}
A group of fluorescent statistical glycopolymers, prepared via reversible addition-fragmentation chain-transfer (RAFT)-based polymerizations, were successfully employed in lectin-mediated bacterial binding studies. The resultant glycopolymers contained three different monomers: $N$-(2hydroxyethyl) acrylamide (HEAA), $N$-(2-aminoethyl) methacrylamide (AEMA) and $N$-(2-glyconamidoethyl)methacrylamides possessing different pendant sugars. Low dispersities $(\leq 1.32)$ and predictable degrees of polymerization were observed among the products. After the polymerization, the glycopolymers were further modified by different succinimidyl ester fluorophores targeting the primary amine groups on AEMA. With their binding specificities being confirmed by testing with lectin coated agarose beads, the glycopolymers were employed in bacterial binding studies, where polymers containing $\alpha$-galactose or $\beta$-galactose as the pendant sugar were specifically bound by two clinically important pathogens Pseudomonas aeruginosa and Staphylococcus aureus, respectively. This is the first report of using RAFTbased glycopolymers in bacterial binding studies, and the ready access to tri-component statistical glycopolymers
\end{abstract}

Electronic supplementary material The online version of this article (doi:10.1007/s10719-013-9508-4) contains supplementary material, which is available to authorized users.

W. Wang $\cdot$ V. V. Mossine

Department of Biochemistry, University of Missouri, Columbia, MO 65211, USA

\section{L. Chance}

Department of Molecular Microbiology \& Immunology, University of Missouri, Columbia, MO 65212, USA

T. P. Mawhinney $(\bowtie)$

Departments of Biochemistry, and Child Health, University of Missouri, 4 Agriculture Building, Columbia, MO 65211, USA e-mail: mawhinneyt@missouri.edu also warrants further exploration of their utility in other glycobiological applications.

Keywords Glycopolymer $\cdot$ RAFT $\cdot$ Lectin $\cdot$ Bacterial binding

$\begin{array}{ll}\text { Abbreviations } \\ \text { RAFT } & \text { Reversible addition-fragmentation chain-transfer } \\ \text { DP } & \text { Degree of polymerization } \\ \text { CTA } & \text { Chain transfer agent } \\ \text { MEHQ } & \text { Hydroquinone monomethyl ether } \\ \text { AEMA } & N \text {-(2-Aminoethyl) methacrylamide } \\ \text { HEAA } & N \text {-(2-Hydroxyethyl) acrylamide } \\ \text { GPC } & \text { Gel permeation chromatography } \\ \text { PMA } & \text { Poly-methacrylamide/acrylamide } \\ \text { DMF } & \text { Dimethylformamide } \\ \text { GNL } & \text { Galanthus nivalis lectin } \\ M \mathrm{n} & \text { Number-average molar molecular weight } \\ M \mathrm{w} & \text { Weight-average molar molecular weight }\end{array}$

\section{Introduction}

In the past two decades, the use of synthetic glycopolymers in biochemical and biomedical research areas has acquired widespread attention. Various types of glycoconjugates were applied in studies of lectin recognition process [1-3], drug and gene delivery systems $[2,4,5]$, disease treatments [6-9], to note a few. Among different designs of glycoconjugate structures, linear glycopolymers with pendant carbohydrate moieties have certain advantages because of the inherent flexibility, efficacy, and their structural comparability with some natural glycoproteins, making them very suitable for cell-carbohydrates recognition studies [3]. In our clinical research, we are particularly interested in the lectin-carbohydrate interactions of key pathogenic bacteria with surface carbohydrates that are found on human tissue cell surfaces and extracellular matrices, a process 
that is considered to be highly involved in the initial step of bacterial adhesion and the persistence of some infections [10, 11]. Many important human respiratory pathogenic bacteria, like Pseudomonas aeruginosa, Staphylococcus aureus, Helicobacter pylori, Escherichia coli, etc., have been widely studied in their lectin binding behaviors [12]. Due to the naturally low binding affinities of many lectins to target carbohydrates, especially monosaccharides, multivalent glycoconjugates possessing higher lectin binding affinities are of great advantage in studying bacterial lectins [3]. Our initial success with the use of commercially available polyacrylamidebased glycoconjugates in the phenotypic expression of lectins of human respiratory pathogenic bacteria prompted us to develop a facile approach to well-defined polymers that would allow for varied pendant carbohydrates, along with different fluorescent labels.

In this pursuit, we turned our attention to a type of living or controlled radical polymerization using reversible additionfragmentation chain-transfer agents (RAFT) [13] that have been successfully applied in the synthesis of glycopolymers. Specifically, the RAFT reactions demonstrate tolerance of a diversity of participating monomers and reaction conditions, as well as, the low dispersity of the products [14-16], all of which are desirable characteristics. On the subject matter of RAFT, and its utilization in preparing glycopolymers, several excellent reviews have been published [16-18]. Tri-component glycopolymers have also been synthesized through RAFTbased reactions, however, most of them either used stepped polymerizations to prepare tri-block copolymers [19-21] or did not possess anomeric pendant sugars appropriate for lectin-binding studies [22]. To the best of our knowledge, this is the first report of well-defined statistical tri-component glycopolymers prepared via one-step RAFT reactions, which possess varied pendant carbohydrates, the versatility of postmodification with varied fluorescent labels, and demonstrated utility in targeted lectin-mediated bacterial binding.

\section{Materials and methods}

\section{Materials}

Unless mentioned otherwise, all chemicals were used as received. $N$-(2-aminoethyl) methacrylamide hydrochloride was purchased from Polysciences (Warrington, PA). Texas Red-X succinimidyl ester and 5-(and-6)-carboxyfluorescein succinimidyl ester were bought from Molecular Probes (Grand Island, NY). Marasmius oreades agglutinin coated lectin beads were obtained from EY laboratories (San Mateo, CA), Galanthus nivalis lectin (GNL) and peanut agglutinin lectin beads from Vector Laboratories (Burlingame, CA). Bacteria strains were from ATCC (Manassas, VA). TOSOH TSK-GEL G4000 PWxl $(30 \mathrm{~cm} \times 7.8 \mathrm{~mm})$ and G4000 SW
$(30 \mathrm{~cm} \times 7.5 \mathrm{~mm})$ HPLC columns were from Fisher Scientific (Pittsburgh, PA). Anion-exchange resin (Amberlite IRN-78 hydroxide-form, 80 mesh), cation-exchange resin (Dowex $50 \mathrm{~W} \times 8,200 \mathrm{mesh})$, hydroquinone monomethyl ether (MEHQ), Orange II sodium salt, $N$-(2-hydroxyethyl) acrylamide (HEAA), and other chemicals, not noted above, were purchased from Sigma-Aldrich Chemicals (St. Louis, MO).

Synthesis of disaccharides

Disaccharides employed in this study, namely $\beta$-Dgalactopyranosyl-( $(1 \rightarrow 6)$-D-glucose (allolactose) and $\alpha$-Dmannopyranosyl- $(1 \rightarrow 6)$-D-glucose were prepared through a modified Koenigs-Knorr reaction. As an example, $1.0 \mathrm{~g}$ of 1 , 2,3,4-tetra- $O$-acetyl- $\beta$-D-glucopyranose [23] $(2.87 \mathrm{mmol})$ was dissolved in $10.0 \mathrm{~mL}$ dry $\mathrm{CH}_{3} \mathrm{CN}$. To the solution, $1.2 \mathrm{~g}$ of 2,3,4,6-tetra- $O$-acetyl- $\alpha$-D-galactopyranosyl bromide ( $2.92 \mathrm{mmol}$ ) and $0.8 \mathrm{~g}$ mercury (II) cyanide $(3.12 \mathrm{mmol})$ were added. The reaction was stirred for $16 \mathrm{~h}$ under an argon atmosphere at room temperature, at which time $2.0 \mathrm{~mL}$ of pyridine and acetic anhydride were added. The stirring continued for $5 \mathrm{~min}$ at $60{ }^{\circ} \mathrm{C}$, at which time the volume of the reaction mixture was reduced in vacuo. The syrupy residue was then redissolved in $200 \mathrm{~mL}$ of $\mathrm{CH}_{2} \mathrm{Cl}_{2}$, washed successively with water, saturated $\mathrm{NaHCO}_{3}$, and brine, then dried over $\mathrm{MgSO}_{4}$ and concentrated in vacuo. The residue was purified by flash chromatography on a silica gel column (70230 mesh, $60 \AA, 15 \times 50 \mathrm{~mm}$, ethyl acetate/hexane 1:1), yielding $1,2,3,4,2^{\prime}, 3^{\prime}, 4^{\prime}, 6^{\prime}$-octa- $O$-acetyl- $\beta$-allolactose (per- $O$ acetyl- $\beta$-allolactose) ( $1.65 \mathrm{~g}, 85 \%$ yield) as a colorless syrup.

Under an atmosphere of dry nitrogen, per- $O$-acetyl- $\beta$ allolactose $(1.0 \mathrm{~g}, 1.47 \mathrm{mmol})$ was then dissolved in $150 \mathrm{~mL}$ dry $\mathrm{MeOH}$, to which was added, with rapid stirring, $1.5 \mathrm{~mL}$ of a sodium methoxide solution ( $25 \mathrm{wt} . \%$ in dry $\mathrm{MeOH}$ ) over a $2 \mathrm{~min}$ period. The reaction was stirred for an additional $30 \mathrm{~min}$ at room temperature and stopped by the addition of cationexchange resin (Dowex $50 \mathrm{~W} \times 8, \mathrm{H}^{+}$form). The resin was removed by filtration and the filtrate evaporated in vacuo to yield allolactose $(0.49 \mathrm{~g}, 97 \%$ yield).

Synthesis of $6-O-\alpha$-D-mannopyranosyl-D-glucose, prepared in a similar manner, yielded $0.56 \mathrm{~g}(80 \%$ yield) of the disaccharide.

Synthesis of disaccharide lactones

Disaccharides melibiose, lactose, allolactose, and 6-O- $\alpha-\mathrm{D}-$ mannopyranosyl-D-glucose, employed in this study, were first oxidized to their corresponding lactones according to Moore et al. [24]. As an example, $2.0 \mathrm{~g}$ of melibiose $(5.84 \mathrm{mmol})$ were dissolved in $4.0 \mathrm{~mL}$ of water, diluted with $5.0 \mathrm{~mL}$ $\mathrm{MeOH}$, and then added to $40 \mathrm{~mL}$ of $\mathrm{MeOH}$ containing $2.9 \mathrm{~g}$ of iodine at $40{ }^{\circ} \mathrm{C}$. With stirring, $70 \mathrm{~mL}$ of $4 \%(\mathrm{w} / \mathrm{v}) \mathrm{KOH}$ in $\mathrm{MeOH}$ was then added dropwise over a period of $30 \mathrm{~min}$ until 
the iodine color completely disappeared. The mixture was then cooled on ice for $1 \mathrm{~h}$. The precipitate of potassium melibionate was then filtered, rinsed with cold $\mathrm{MeOH}$, recrystallized from $100 \mathrm{~mL} \mathrm{MeOH/water} \mathrm{(9:1,} \mathrm{v/v),} \mathrm{then} \mathrm{dried} \mathrm{in}$ vacuo. The resulting melibionic acid salt was then dissolved in $10 \mathrm{~mL}$ water and converted into its free acid form by passing the solution through a strongly acidic cationexchange column (Dowex $50 \mathrm{~W} \times 8, \mathrm{H}^{+}$form) and then freeze-dried to yield approximately $2.0 \mathrm{~g}$. This was then dissolved in a minimal amount of $\mathrm{MeOH}(\sim 3.0 \mathrm{~mL})$ to which absolute $\mathrm{EtOH}$ was added until the solution turned just cloudy, at which time the solvents were evaporated in vacuo. This was repeated 4 times to yield melibiono-1,5-lactone (1.94 g, $98 \%$ yield). Other disaccharides, oxidized in a similar manner, produced comparable yields ( $>95 \%$ ).

\section{Synthesis of glycomonomers}

2-Gluconamidoethyl methacrylamide (GAEMA) was prepared according to a published protocol [19] and 2lactobionamidoethyl methacrylamide (LAEMA) was prepared with some modifications. To the solution of $1.0 \mathrm{~g}$ of lactobiono-1,5-lactone $(2.94 \mathrm{mmol})$ in $3.0 \mathrm{~mL}$ of $\mathrm{MeOH}$, were added $N$-(2-aminoethyl) methacrylamide hydrochloride (AEMA hydrochloride, $0.58 \mathrm{~g}, 3.53 \mathrm{mmol}$ ) and $1.0 \mathrm{mg}$ hydroquinone monomethyl ether (MEHQ, an inhibitor of self-polymerization) in $2.0 \mathrm{~mL}$ of $\mathrm{MeOH}$ and $1.0 \mathrm{~mL}$ of triethylamine. The mixture was stirred at room temperature for $48 \mathrm{~h}$, at which time $20 \mathrm{~mL}$ of water was added. Then, $\mathrm{MeOH}$ and triethylamine were removed from the mixture in vacuo. To remove any remaining lactobionate, the resulting aqueous solution was passed through an anion exchange column (Amberlite IRN-78, $\mathrm{OH}^{-}$form, $10 \times 20 \mathrm{~mm}$ ) into a receiving beaker containing $1.0 \mathrm{mg}$ of MEHQ. Residual triethylamine was then removed from the eluate in vacuo. Dowex $50 \mathrm{~W} \times 8\left(\mathrm{H}^{+}\right)$was added portionwise to the solution, until no ninhydrin reactive material remained. The mixture was then filtered and freeze-dried. Removal of MEHQ from the freeze-dried product was accomplished by dissolving the material in a minimum amount of $\mathrm{MeOH}$, which was then added to ice cold acetone to precipitate LAEMA. Following filtration and drying, LAEMA (0.89 g, $65 \%$ yield) was obtained as white powder. Other glycomonomers listed in Table 1 were prepared in the same manner with comparable yields.

Kinetic experiment for the RAFT tri-component polymerization of GAEMA

To a $5 \mathrm{ml}$ Schlenk tube equipped with a septum, was added $2.4 \mathrm{~mL}$ water containing $128.5 \mathrm{mg}$ of GAEMA $(419.5 \mu \mathrm{mol})$, $10.3 \mathrm{mg}$ AEMA hydrochloride $(62.9 \mu \mathrm{mol})$ and $166 \mu \mathrm{L}$ of HEAA $(1615.1 \mu \mathrm{mol})$ thus producing a monomers molar ratio of 20:3:77, respectively. To the solution were then sequentially added $0.3 \mathrm{~mL}$ dimethylformamide (DMF) containing $3.1 \mathrm{mg}$ of (4-cyanopentanoic acid)-4-dithiobenzoate [11 $\mu \mathrm{mol}$, chain transfer agent (CTA)], and $0.3 \mathrm{~mL}$ DMF containing $1.5 \mathrm{mg} 4,4^{\prime}$ - azobis (4-cyanovaleric acid) (5.4 $\mu \mathrm{mol}$, initiator). The resulting molar ratio of $[\mathrm{M}]_{0}:[\mathrm{CTA}]:[$ Initiator] was $380: 2: 1$, where $[\mathrm{M}]_{0}$ is the initial total monomers concentration. The solution was then degassed with 3 freeze-evacuatethaw cycles and the Schlenk tube transferred to a water bath at $70^{\circ} \mathrm{C}$. At each time point of the copolymerization $(2,4,7,11$, 24 , and $35 \mathrm{~h}$ ), $200 \mu \mathrm{L}$ of the solution were withdrawn with an argon-purged gas tight syringe and precipitated in $10 \mathrm{~mL}$ of cold acetone containing $1.0 \mathrm{mg}$ of MEHQ. The precipitates were dried in vacuo and prepared for gel permeation chromatography (GPC) and NMR analysis, as noted below. The conversion rates of GAEMA were determined by comparing the proton signal changes from both $\mathrm{H}-2(\delta 4.30-4.40)$ and $\mathrm{H}-$ 3 ( 8 4.05-4.15) (Supplementary Fig. S9).

One-step tri-component RAFT-based copolymerization (see Scheme 1)

To a $1 \mathrm{ml}$ Schlenk tube equipped with a septum, was added $0.4 \mathrm{~mL}$ water containing $21.4 \mathrm{mg}$ of GAEMA or $32.8 \mathrm{mg}$ of disaccharide monomers (70.0 $\mu$ mol, Table 1), $1.7 \mathrm{mg}$ AEMA $(10.5 \mu \mathrm{mol})$ and $27.5 \mu \mathrm{L}$ HEAA $(270 \mu \mathrm{mol})$, thus having a monomer molar ratio of 20:3:77, respectively. To the monomer solution were then sequentially added $50 \mu \mathrm{L}$ DMF containing $0.53 \mathrm{mg}$ of (4-cyanopentanoic acid)-4-dithiobenzoate $(1.9 \mu \mathrm{mol})$ and another $50 \mu \mathrm{L}$ DMF containing $250 \mu \mathrm{g}$ of 4 , 4'-azobis-(4-cyanovaleric acid) $(0.9 \mu \mathrm{mol})$ resulting in a molar ratio of $[\mathrm{M}]_{0}:[\mathrm{CTA}]:[$ Initiator] to be $380: 2: 1$. The mixture was
Table 1 Synthesized glycomonomers, glycopolymers and their abbreviations

a PMA stands for polymethacrylamide/acrylamide

\begin{tabular}{|c|c|c|}
\hline \multirow[t]{2}{*}{ Glycomonomer (yield) } & \multicolumn{2}{|l|}{ Abbreviations } \\
\hline & Glycomonomers & Glycopolymers \\
\hline 2-Gluconamidoethyl methacrylamide (98 \%) & GAEMA & PMA ${ }^{\mathrm{a}}$-GAEMA \\
\hline 2-Lactobionamidoethyl methacrylamide (65\%) & LAEMA & PMA-LAEMA \\
\hline 2-Allolactobionamidoethyl methacrylamide (59 \%) & ALAEMA & PMA-ALAEMA \\
\hline 2-Melibionamidoethyl methacrylamide (68\%) & MAEMA & PMA-MAEMA \\
\hline 6-O- $\alpha$-D-mannopyranosyl-D-gluconamidoethyl methacrylamide (64\%) & MGAEMA & PMA-MGAEMA \\
\hline
\end{tabular}


Scheme 1 Illustration of the synthesis of fluorescent glycopolymers PMA-ALAEMAFluorescein containing $\beta$ galactoside as the pendant sugar

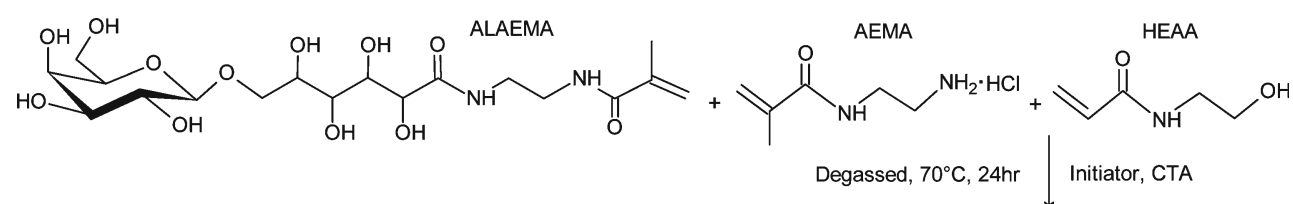

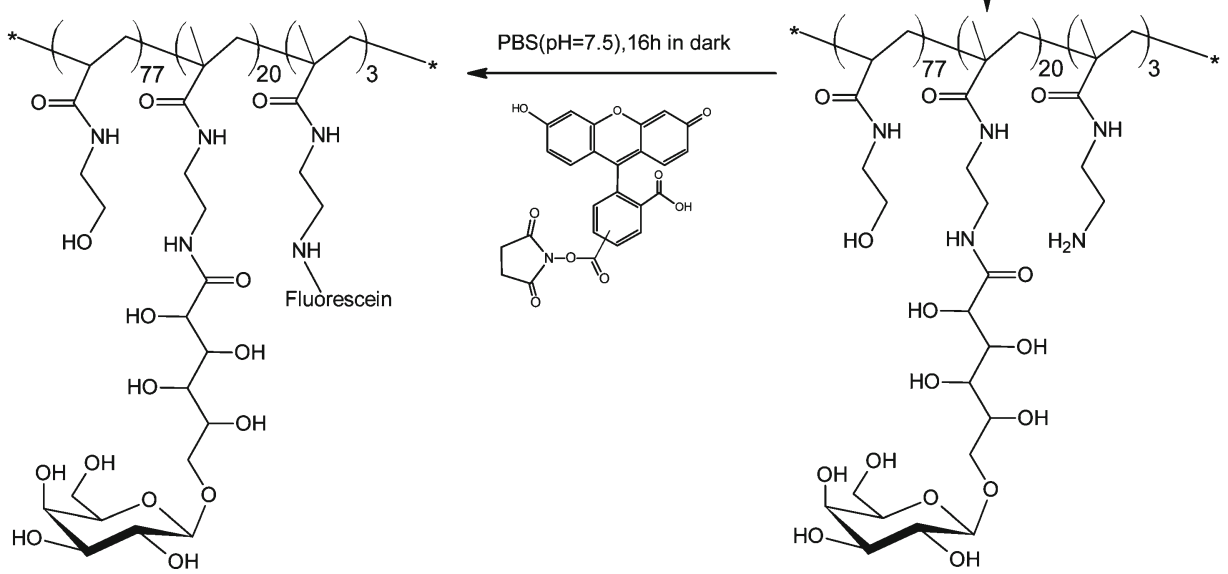

degassed with 3 freeze-evacuate-thaw cycles and transferred to a water bath at $70^{\circ} \mathrm{C}$ for $24 \mathrm{~h}$. At this time, an aliquot of the solution $(100 \mu \mathrm{L})$ was treated with $20 \mathrm{~mL}$ of ice cold acetone and the precipitated polymers were analyzed by GPC, as described below. The remainder of the solutions were then dialyzed against deionized water $(6 \times 2 \mathrm{~L})$ over a period of $24 \mathrm{~h}$ $(\mathrm{MWCO}=3,500)$ and then lyophilized. The resultant statistical poly-methacrylamide/acrylamide (PMA) copolymers containing pendant glyconamides, $4-O-\beta-\mathrm{D}$-galactopyranosyl-Dgluconamide (lactobionamide), 6- $O-\beta-\mathrm{D}$-galactopyranosylD-gluconamide (allolactobionamide), 6-O- $\alpha$-Dgalactopyranosyl-D-gluconamide (melibionamide) or 6$O$ - $\alpha$-D-mannopyranosyl-D-gluconamide, were obtained. For ease of discussion, they are abbreviated as PMA-GAEMA, PMA-LAEMA, PMA-ALAEMA, PMA-MAEMA, and PMA-MGAEMA, respectively (Table 1).

Synthesis of PMA-ALAEMA with different degree of polymerization (DP)

To test the ability of the tri-component RAFT reaction to produce varied copolymer lengths, reactions with varied concentrations of CTA and initiator were performed (Table 2). A parallel reaction without using any CTA was performed, as well. For all reactions, the amounts of monomers used and the reaction procedures were exactly the same as described in the section above. The synthesized PMA-ALAEMA glycopolymers with different DPs were characterized on GPC.

Post-modification of glycopolymers with fluorophores

Glycopolymers $(5.0 \mathrm{mg}$ ) containing $\sim 0.9 \mu$ mole of primary amine functional groups were individually dissolved in $0.9 \mathrm{~mL}$ phosphate buffered saline (PBS, $0.1 \mathrm{M}$ sodium phosphate, $0.15 \mathrm{M} \mathrm{NaCl}, \mathrm{pH}$ 7.5). To each solution, with rapid stirring, was slowly added $100 \mu \mathrm{L}$ DMF containing $0.6 \mathrm{mg}$ of carboxyfluorescein succinimidyl ester $(1.3 \mu \mathrm{mol})$, or $1.1 \mathrm{mg}$ of Texas Red-X succinimidyl ester $(1.3 \mu \mathrm{mol})$. The reactions were gently stirred for $16 \mathrm{~h}$ in the dark and then dialyzed against $6 \times 2 \mathrm{~L}$ distilled deionized water over a period of $24 \mathrm{~h}(\mathrm{MWCO}=3,500)$. Following lyophilization, a colored flocculent product was obtained for each glycopolymer. In some experiments, to confirm the completeness of reaction between the primary amines and fluorophore succinimidyl esters, purified labeled glycopolymers were retreated with an additional fluorophore reagent and the products tested for any increase in fluorescence.

Binding tests of the synthetic glycopolymers with lectin coated agarose beads

The lectin-binding specificities of the synthesized glycopolymers were first probed by testing with plant lectin-coated agarose beads. As an example of the binding test protocol, a $50 \mu \mathrm{L}$

Table 2 Parameters of reactions synthesizing PMA-ALAEMA with different DP

\begin{tabular}{|c|c|c|c|c|c|}
\hline Copolymerizations & $\begin{array}{l}\text { Amount } \\
\text { of CTA } \\
\text { used,/ } \\
\text { mg }\end{array}$ & $\begin{array}{l}\text { Amount } \\
\text { of } \\
\text { initiator } \\
\text { used,/mg }\end{array}$ & $\begin{array}{l}\text { Target } \\
\text { DP, } \\
{[\mathrm{M}]_{0} /} \\
{[\mathrm{CTA}]}\end{array}$ & $\begin{array}{l}\text { Reaction } \\
\text { yield after } \\
\text { dialysis, } \\
\%\end{array}$ & $\begin{array}{l}\text { Actual } \\
\mathrm{DPs}^{\mathrm{a}}\end{array}$ \\
\hline \#1 & 1.00 & 0.25 & 97 & 45 & 26 \\
\hline$\# 2$ & 0.53 & 0.25 & 190 & 78 & 101 \\
\hline \#3 & 0.25 & 0.25 & 386 & 81 & 260 \\
\hline \#4 & 0 & 2.00 & NA & 98 & 382 \\
\hline
\end{tabular}


suspension of GNL coated agarose beads, which binds $\alpha$ mannose specifically, were washed three times with $1.5 \mathrm{~mL}$ PBS and resuspended in $0.5 \mathrm{~mL}$ PBS. To the mixtures were added $3 \mu \mathrm{g}$ of PMA-MGAEMA-Fluorescein or PMAMAEMA-Fluorescein, respectively. Following a $1 \mathrm{~h}$ incubation in the dark at room temperature, the mixtures were each then washed three times with $1.5 \mathrm{~mL}$ PBS. In a parallel competitive binding test, the GNL agarose beads were preincubated with $1.0 \mathrm{mg}$ of non-fluorescent PMA-MAEMA or PMA-MGAEMA for $20 \mathrm{~min}$ before the addition of $3 \mu \mathrm{g}$ of PMA-MGAEMA-Fluorescein. The final beads pellets from the binding tests were each resuspended in $1.0 \mathrm{~mL}$ PBS, $4 \mu \mathrm{L}$ aliquots were then subjected to fluorescence microscopy (Olympus BX43, FITC filter used), and $100 \mu \mathrm{L}$ aliquots were taken for measurements of their fluorescence intensities $(\lambda \mathrm{ex} /$ $\lambda \mathrm{em}=490 / 520 \mathrm{~nm}$, slit width $=10 \mathrm{~nm}$ ) on a microplate reader (BioTek Synergy Mx). Employing the same protocol, Marasmius oreades agglutinin-coated lectin beads were used to confirm the binding with $\alpha$-galactoside containing copolymers, while peanut agglutinin lectin beads were used to probe for $\beta$-galactoside binding.

Lectin-mediated bacterial binding with fluorescent glycopolymers

S. aureus ATCC 25923 and P. aeruginosa ATCC 39018 were separately cultured on either mannitol salt or trypticase soy agar for $24 \mathrm{~h}$. The colonies were then lifted and suspended in $20 \mathrm{~mL}$ of binding solution $\left(155 \mathrm{mM} \mathrm{NaCl}, 1 \mathrm{mM} \mathrm{CaCl}_{2}\right.$, and $1 \%$ bovine serum albumin) to attain a bacterial suspension with an optical density of 1 at $600 \mathrm{~nm}$. For each binding experiment, $100 \mu \mathrm{g}$ of fluorescent glycopolymers, dissolved in $100 \mu \mathrm{L}$ sodium phosphate buffer $(0.3 \mathrm{M}, \mathrm{pH}=7.4)$, were then added to $1.0 \mathrm{~mL}$ of a bacteria suspension to be tested, respectively, and incubated for $2 \mathrm{~h}$ in the dark at $35^{\circ} \mathrm{C}$ with gentle shaking. Specifically, S. aureus was treated with PMAALAEMA-Fluorescein, while PMA-MAEMA-Texas Red was employed for binding to $P$. aeruginosa. In negative control experiments, either PMA-GAEMA-Fluorescein or PMA-GAEMA-Texas Red was used in the incubation. Following incubation, all bacteria-glycopolymer mixtures were then centrifuged $(8,000 \times \mathrm{g}, 10 \mathrm{~min})$ and the pellets were washed three times with $1.2 \mathrm{~mL}$ saline $(155 \mathrm{mM} \mathrm{NaCl}$ containing $1 \mathrm{mM} \mathrm{CaCl}_{2}$ ). The final pellets were then resuspended in $20 \mu \mathrm{L}$ saline and $4 \mu \mathrm{L}$ aliquots were then taken for analysis by fluorescence microscopy. The green and red fluorescencelabeled bacteria in each photo representing one or several glycopolymer-binding $S$. aureus and $P$. aeruginosa respectively were quantified by the software cellSens Dimension (Olympus, Fig. S14).

Employing the same protocol described above, S. aureus ATCC 25923 was also separately tested with $100 \mu \mathrm{g}$ of fluorescein-labeled PMA-LAEMA, PMA-ALAEMA, PMA-
MAEMA, and PMA-GAEMA in order to compare their carbohydrate-binding specificities. The bacteria pellets after three washings were resuspended in $100 \mu \mathrm{L}$ PBS $(\mathrm{pH}=8)$, and the fluorescence intensities were measured on the microplate reader. All binding experiments were performed in triplicate.

Analysis

${ }^{1} \mathrm{H}$ and ${ }^{13} \mathrm{C}$ NMR spectra of samples dissolved in $\mathrm{D}_{2} \mathrm{O}$ were recorded on a Bruker Avance $800 \mathrm{MHz}$ spectrometer. ${ }^{1} \mathrm{H}$ and ${ }^{13} \mathrm{C}$ spectra were recorded at 800.14 and $201.19 \mathrm{MHz}$, respectively. Glycomonomers, dissolved in $\mathrm{MeOH} /$ water 50:50 (v/ v) were subjected to direct electrospray mass spectrometry analyses, utilizing a Thermo Scientific LTQ Orbitrap XL hybrid Fourier transform mass spectrometer. Molecular weights $(M \mathrm{w}, M \mathrm{n})$ and the dispersity $(M \mathrm{w} / M \mathrm{n})$ of the glycopolymers were derived against a calibration curve from polyethylene glycol standards (MW: 200-1,200,000 g/mol) using a Waters Alliance HPLC system equipped with a refractive index detector (Waters e2695, 2414) and TOSOH TSKGEL G4000 PWxl and a TSK-GEL G4000 SW GPC columns using $0.1 \mathrm{M}$ Tris $/ 0.1 \mathrm{M}$ sodium chloride buffer $(\mathrm{pH}=7)$ as eluent at a flow rate of $0.6 \mathrm{~mL} / \mathrm{min}$. The actual concentrations of primary amine functional groups within the glycopolymers were quantified with Orange II according to a published protocol [25]. Total carbohydrate content of the synthesized glycopolymers was analyzed according to a published method [26]. Elemental analysis was performed by Galbraith Laboratories, Knoxville, TN.

\section{Results and discussion}

\section{Synthesis of glycomonomers}

In order to provide for desired conformations of pendant sugars presented by glycopolymers to plant and bacterial lectins, we have chosen disaccharides lactose, melibiose, allolactose and $\alpha$-D-mannopyranosyl- $(1 \rightarrow 6)$-D-glucose as the specific glycoside sources. All disaccharides were then oxidized with iodine and dehydrated to their respective lactones. These disaccharide lactones, and gluconolactone, were then reacted with the primary amine functional group on AEMA to produce a group of glycomonomers, listed in Table 1. While GAEMA and LAEMA have been previously reported [4, 19], glycomonomers ALAEMA, MAEMA, and MGAEMA, are novel glycosynthons designed to provide $\alpha$ galactoside, $\beta$-galactoside and $\alpha$-mannoside, respectively, as the pendant carbohydrate residues. In contrast to the report on the preparation of LAEMA [19], we initially obtained varied amounts of the product which was also of an unsatisfactory purity. A modified purification procedure was thus developed 
for the disaccharide lactone, which uses cation and anionexchange resins, sequentially, to remove unreacted AEMA and disaccharide acids, respectively, resulting in less variable yields of $59 \%$ to $68 \%$ (Table 1). The details of individual syntheses are given in the Supplementary material. Characterizations performed by NMR spectroscopy, mass spectrometry, and elemental analysis confirmed the high purities of the products (Supplementary Fig. S1-8). ${ }^{1} \mathrm{H}$ NMR spectroscopy of the glycomonomers also confirmed the correct configurations at the anomeric carbons in allolactose and $\alpha$-Dmannopyranosyl-( $1 \rightarrow 6)$-D-glucopyranose (Supplementary Fig. S2, 4).

Kinetic experiment for the RAFT tri-component polymerization of GAEMA

GPC traces of the PMA-GAEMA copolymers at different time points indicate that the RAFT-based polymerization was well-controlled, as evidenced by the consecutive low dispersities $(<1.3)$ of the products and of the steady evolution of the $M \mathrm{n}$ (Fig. 1). As expected, the examination of developing copolymers by ${ }^{1} \mathrm{H}$ NMR indicated that the consumption of GAEMA and HEAA monomers in the reaction proceeded at different rates with GAEMA being consumed somewhat faster. This observation is a focus of an ongoing investigation. Overall, $>95 \%$ of the conversion was completed in the first 24 h (Fig. 1b).

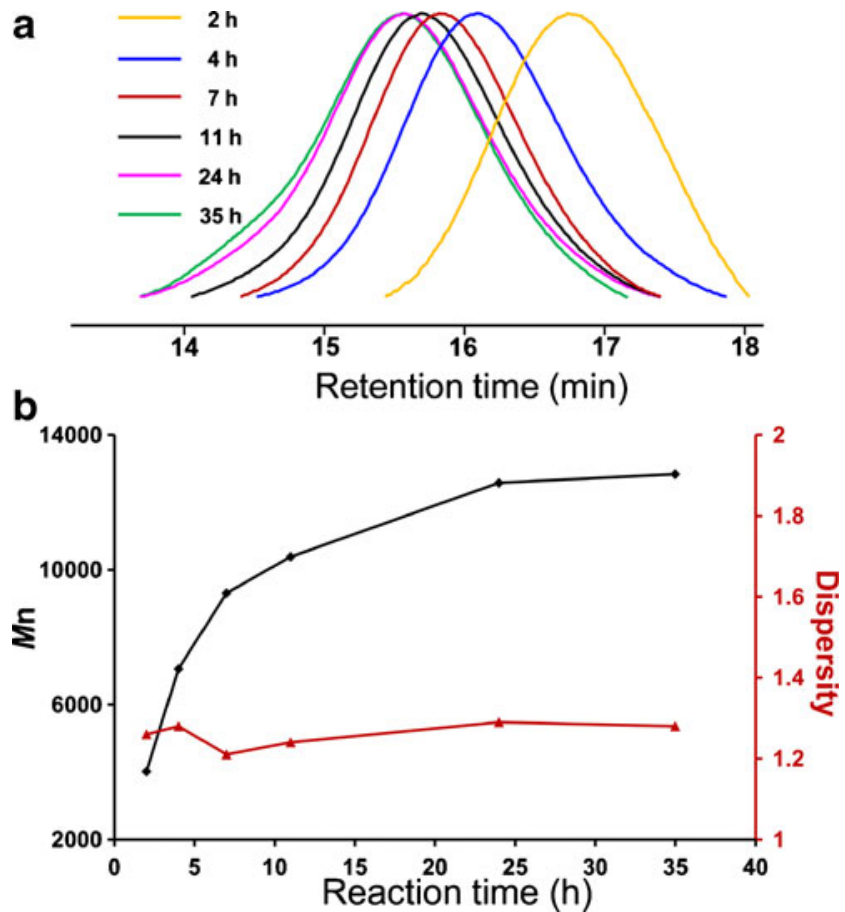

Fig. 1 Kinetic study for the RAFT polymerization of PMA-GAEMA. a Gel permeation chromatography traces of the copolymers indicating steady evolution of the copolymers with time. b $M \mathrm{n}$ dispersities of the glycopolymers over time. $\left([\mathrm{M}]_{0}:[\mathrm{CTA}]:[\right.$ Initiator $]=380: 2: 1 ;[\mathrm{M}]_{0}=0.7 \mathrm{M}$; solvent, $\mathrm{H}_{2} \mathrm{O} / \mathrm{DMF}=4: 1$ )
RAFT-based synthesis of glycopolymers

In this study, a facile one-step RAFT-mediated tri-component copolymerization strategy was employed. Compared to the biblock or tri-block glycopolymers prepared through stepped RAFT-controlled polymerizations [15, 19, 27], this one-step reaction should provide for a more random distribution of the glycomonomers in the products, as seen in naturally occurring glycoproteins, mucous glycoproteins and glycolipids. In this work, we prepared glycopolymers that contain $20 \mathrm{~mol} \%$ of glycomonomer, HEAA ( $77 \mathrm{~mol} \%$ on polymer) as spacer, and AEMA ( $3 \mathrm{~mol} \%)$ as targets for post-modifications with fluorophores and then employed them in a lectin-binding study similar to that reported by Bovin in the use of early neoglycoconjugates [28]. With the use of RAFT reactions, synthesized glycopolymers with different pendant sugars on the gluconamide linker (Table 1) demonstrated low dispersities ( $\leq 1.32$ ), very similar GPC traces and $M \mathrm{n}$ (Fig. 2, Table 3). As can be seen in Fig. 2, when plotted against the elution profiles of these glycopolymers, only PMA-GAEMA displayed a smaller $M \mathrm{n}$ due to the absence of a pendant pyranose. For all glycopolymers, these results demonstrate a high reproducibility of copolymerization and, following individual analysis of product components (i.e., carbohydrates and primary amine functional groups (Table 3)), it was determined that the ratio of incorporated monomers in the respective glycopolymers reflected the stoichiometric ratio of monomers employed in the initial RAFT reactions. In other words, the stoichiometry of components in RAFT reactions predictably defined the respective product composition. Structural confirmation of the resultant glycopolymers was performed by ${ }^{1} \mathrm{H}$ - and ${ }^{13} \mathrm{C}-\mathrm{NMR}$ (Fig. 3, and supplementary Fig. S9-12).

That the pendant sugars are located on a gluconamide linker, is of special note, in that it results in formation of polymers that are more physiologically relevant because of the hydrophilic nature of the polysaccharides chains on many natural glycoproteins.

To test the ability of CTA to control the DPs and dispersity of the product copolymers, varied amounts of CTA (Table 2)

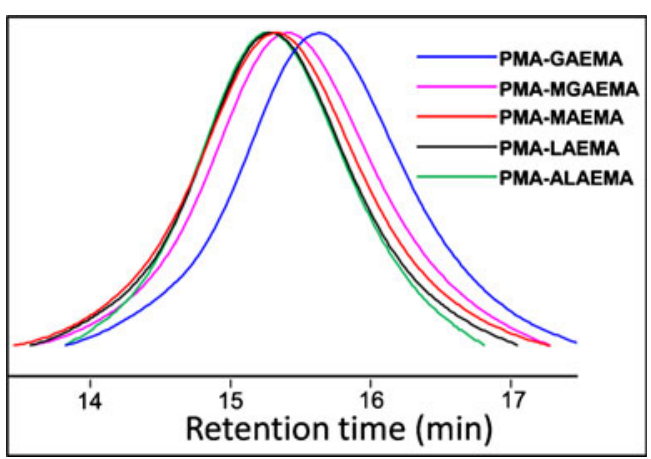

Fig. 2 Gel permeation chromatography traces of RAFT-based glycopolymers. $\left([\mathrm{M}]_{0}:[\mathrm{CTA}]:[\right.$ Initiator $]=380: 2: 1 ;[\mathrm{M}]_{0}=0.7 \mathrm{M}$; solvent, $\left.\mathrm{H}_{2} \mathrm{O} / \mathrm{DMF}=4: 1\right)$ 
Table 3 Summary of the synthetic parameters and actual compositions of the RAFT glycopolymers

\begin{tabular}{|c|c|c|c|c|c|c|c|}
\hline Glycopolymer & Pendant sugar(linkage) & $\begin{array}{l}M \mathrm{n}, \mathrm{GPC} \\
\mathrm{g} / \mathrm{mol}\end{array}$ & $\mathrm{DP}^{\mathrm{a}}$ & $M \mathrm{w} / M \mathrm{n}$ & $\begin{array}{l}\text { Actual content of } \\
\text { glycomonomers, } \mathrm{mol} \%\end{array}$ & $\begin{array}{l}\text { Actual content of } \\
\text { primary amine, } \mathrm{mol} \%\end{array}$ & $\begin{array}{l}\text { Reaction yield } \\
\text { after dialysis, \% }\end{array}$ \\
\hline PMA-GAEMA & None & 13696 & 89 & 1.32 & NA & 2.7 & 70 \\
\hline PMA-MAEMA & $\alpha$-galactose $(1 \rightarrow 6)$ & 17684 & 95 & 1.30 & 21 & 3.3 & 74 \\
\hline PMA-LAEMA & $\beta$-galactose $(1 \rightarrow 4)$ & 18431 & 99 & 1.26 & 19 & 3.2 & 76 \\
\hline PMA-ALAEMA & $\beta$-galactose $(1 \rightarrow 6)$ & 18943 & 101 & 1.21 & 18 & 3.0 & 78 \\
\hline PMA-MGAEMA & $\alpha$-mannose $(1 \rightarrow 6)$ & 16498 & 88 & 1.31 & 16 & 3.4 & 68 \\
\hline
\end{tabular}

${ }^{\text {a }}$ Calculated by $\mathrm{Mn} /\left(0.77 \mathrm{MW} W_{\mathrm{HEAA}}+0.2 \mathrm{M} W_{\text {glycomonomer }}+0.03 M W_{\mathrm{AEMA}}\right)$. Considering actual DP and contents of each monomer in the polymers, these

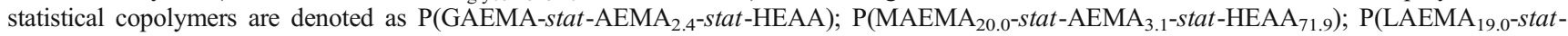

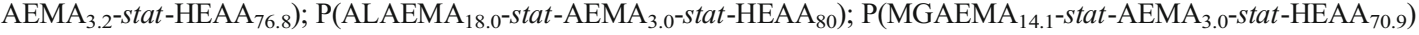

were employed in the polymerizations. A class of PMAALAEMA polymers with determined DPs was prepared and they clearly showed that reactions with RAFT reagents produced polymers that possessed considerably lower dispersities than polymers prepared without any CTA in the reaction (Fig. 4).

\section{Post-modification of glycopolymers with fluorophores}

The reaction of primary amine functional groups with a variety of reactive fluorophores is a technique frequently employed in protein labeling. This versatility was incorporated into our investigation by post-modifying the amine functional groups in our purified glycopolymers by separately reacting them with either activated succinimidyl esters of carboxyfluorescein or Texas Red-X fluorophores.

After $16 \mathrm{~h}$ of reaction in PBS buffer, and $24 \mathrm{~h}$ dialysis against water, respective fluorescent polymers (i.e., PMA-MAEMATexas Red or PMA-GAEMA-Texas Red, and PMAALAEMA-Fluorescein or PMA-GAEMA-Fluorescein) were obtained, with no detectable degradation of the polymers, as determined by GPC analysis (data not shown). Compared to other labeling protocols applied to glycopolymers [2, 19], this present method of post-modification is both simpler and amenable to choice of fluorescent label desired for different experimental designs. In our opinion, most of the water-soluble aminereactive fluorophores, biotins or quantum dots [22], should be suitable for labeling of these synthesized glycopolymers.

Binding of synthetic glycopolymers with plant lectin coated agarose beads

In order to assess the lectin-binding specificities of the synthesized glycopolymers, each glycopolymer product was individually tested and confirmed with its corresponding lectincoated agarose beads. As an example, the binding results with $\alpha$-mannose-specific lectin GNL are presented here. Figure 5a demonstrates the negligible binding of GNL beads with PMAMAEMA-Fluorescein which contains $\alpha$-galactose as the pendant sugar. In contrast, the $\alpha$-mannose-containing polymer
PMA-MGAEMA-Fluorescein showed very strong binding (Fig. 5b). To further validate the binding specificity with the synthesized glycopolymers, this binding was competitively inhibited when the GNL beads were pre-incubated with $1 \mathrm{mg}$ of non-fluorescent PMA-MGAEMA (Fig. 5c), and, when pretreated with $1 \mathrm{mg}$ of PMA-MAEMA, no such effects were observed (Fig. 5d). The fluorescence intensities that were measured on the microplate reader (Fig. S13) were consistent with the observation by microscopy. Similarly, the binding specificities of the three different galactosecontaining glycopolymers were confirmed by employing agarose beads coated with either Marasmius oreades agglutinin or peanut agglutinin lectin and the respective competitive inhibition by the corresponding non-fluorescent glycopolymers (data not shown).

Lectin-mediated binding of bacteria with fluorescent glycopolymers

Having established the specific affinities of the synthetic glycopolymers towards plant lectin-coated agarose beads, application of these polymers with clinically relevant bacterial strains was performed. The well-studied $\alpha$-galactose-binding P. aeruginosa lectin PA-IL, which plays a crucial role in their opportunistic infections $[29,30]$, was first studied. Ideal for this experiment, PMA-MAEMA-Texas Red, possessing $\alpha$ galactose as the pendant sugar, was employed to test its binding ability with this organism. As a negative control, PMA-GAEMA-Texas Red, lacking the pendant $\alpha$-galactose group, was used. In a parallel experiment, employing the same protocol, PMA-ALAEMA-Fluorescein possessing $\beta$ galactose residues was tested for the recognition of $S$. aureus, with PMA-GAEMA-Fluorescein used as a negative control. In three sets of repeated experiments, specific and dramatic binding of the respective glycopolymers between the bacteria and pendant sugars was observed by fluorescence microscopy (Fig. 6) when compared with the negative controls which demonstrated an occasional occurrence of non-specific binding (Fig. S14). The weak non-specific binding with the negative controls could be due to associations between a few 
Fig. 3 Assigned ${ }^{1} \mathrm{H}$ - (a) and ${ }^{13} \mathrm{C}$ NMR (b) spectra $\left(\mathrm{D}_{2} \mathrm{O}\right)$ for PMA-ALAEMA a
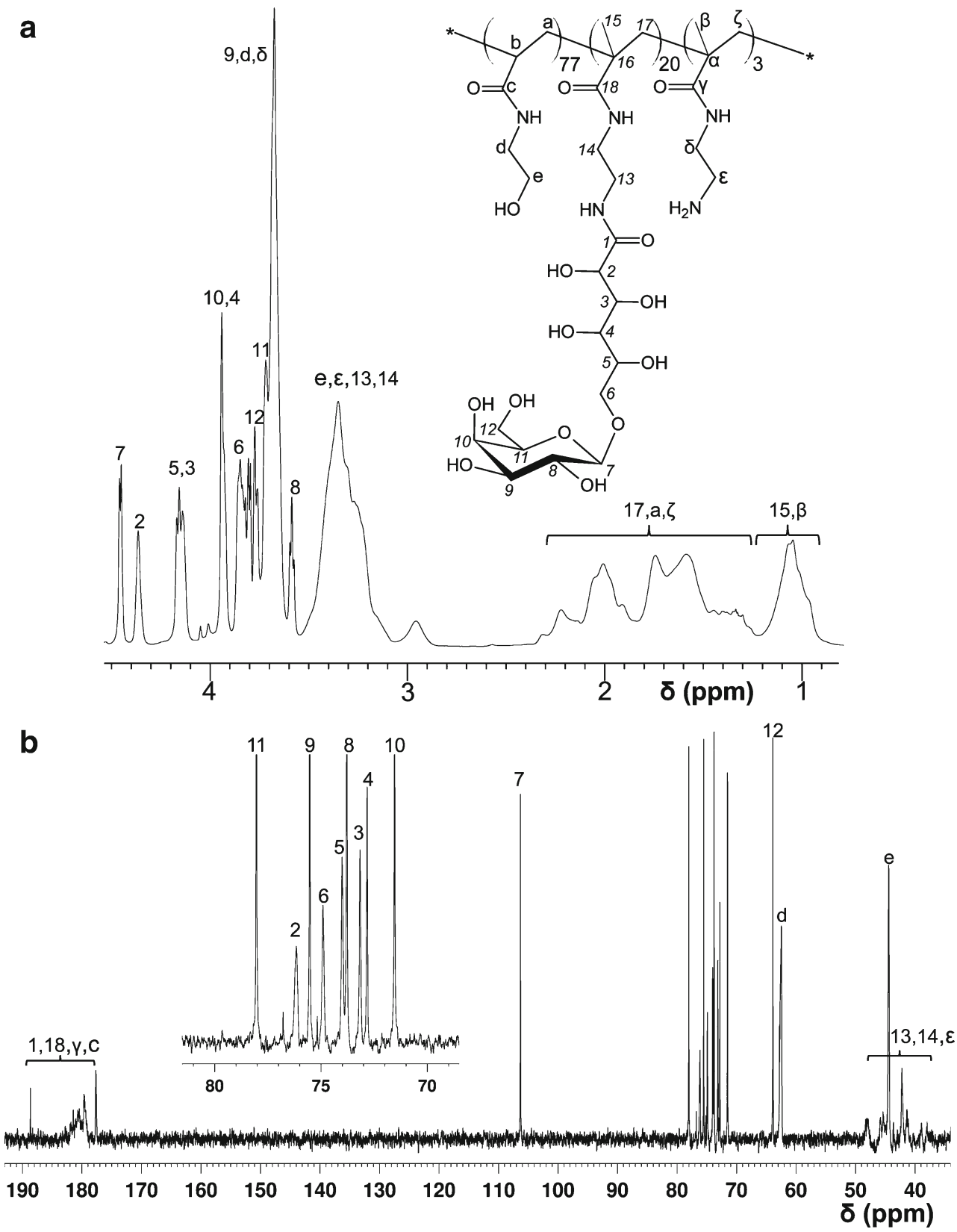

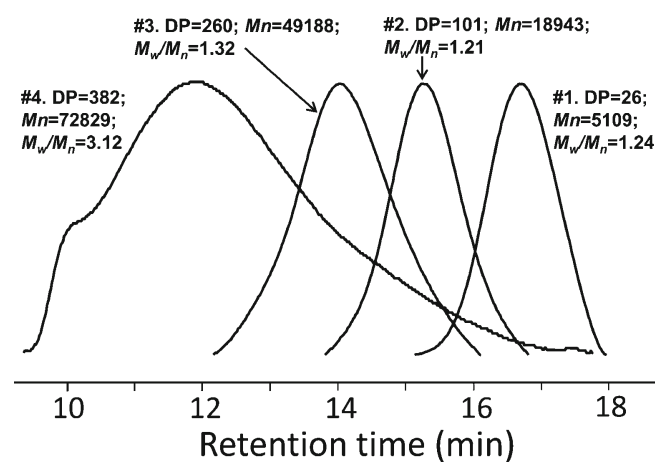

Fig. 4 Gel permeation chromatography traces of PMA-ALAEMA with different DPs from copolymerizations using different amounts of chain transfer agent $\left([\mathrm{M}]_{0}=0.7 \mathrm{M}\right.$; solvent, $\left.\mathrm{H}_{2} \mathrm{O} / \mathrm{DMF}=4: 1\right)$ bacteria and the glycopolymer fluorophores, or possibly some traces unreacted primary amine functional groups remaining on the glycopolymer. The latter hypothesis has been tested by subjecting the fluorescent glycopolymers to a second round of the fluorescent labeling. However, no further increase in fluorescence was noted, nor did this retreatment affect the small amount of the non-specific binding to the bacteria.

In another experiment where different fluorescein-labeled glycopolymers were used to test the carbohydrate-binding specificity of $S$. aureus ATCC 25923, PMA-ALAEMA and PMA-LAEMA, both possessing $\beta$-D-galactose as the pendant sugar, showed dramatically higher binding than either PMAMAEMA, which possesses $\alpha$-D-galactose, or the negative control PMA-GAEMA. These results suggest that this strain 
Fig. 5 Galanthus Nivalis lectin (GNL) coated agarose beads bind $\alpha$-D-mannoside containing glycopolymers, but not those possessing $\alpha$-D-galactoside. PMA-MAEMA-Fluorescein $(3 \mu \mathrm{g})$ showed only a weak nonspecific binding with GNL (a), in contrast to the strong binding between PMA-MGAEMA-

Fluorescein and the beads (b). Pre-incubation of the beads with $1.0 \mathrm{mg}$ of non-fluorescent PMAMGAEMA for 20 min before adding $3 \mu \mathrm{g}$ of PMA-MGAEMAFluorescein dramatically reduced the binding of the latter (c), but the pre-incubation with $1.0 \mathrm{mg}$ of PMA-MAEMA didn't show any competitive inhibition effects (d). Scale bar $=100 \mu \mathrm{m}$
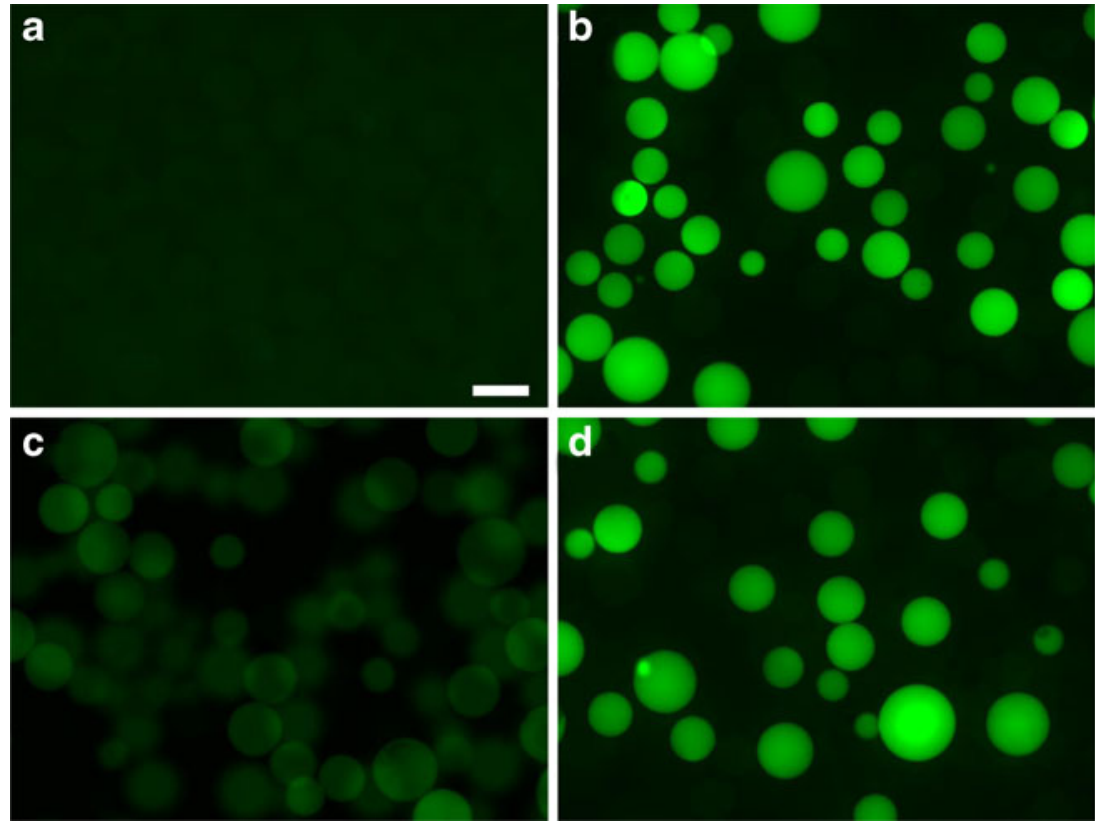

of $S$. aureus has a binding preference for $\beta$-D-galactose (Fig. 7).

Understanding that the outcome of synthesizing a group of tricomponent polymers would produce statistical polymers, we anticipated the possibility of glycopolymer molecules that would not have incorporated any AEMA monomer and thus would not be fluorophore-labeled. Thus, the presence of these unlabeled glycopolymers would then potentially act as binding competitors. Although we did not attempt to determine the percentage of such species, considering the very low possibility of such polymers $\left(4.7 \%\right.$, i.e., $\left.0.97^{100} \approx 0.04755\right)$, their competition effects in the present experiments were not considered to be significant.

As the binding between lectins and monosaccharides is generally very weak, strong interactions most often require multivalency of the sugars $[3,31]$. As the fluorescent-labeled glycopolymers produced in this investigation possess such multivalency (14-20 pendant carbohydrate residues per

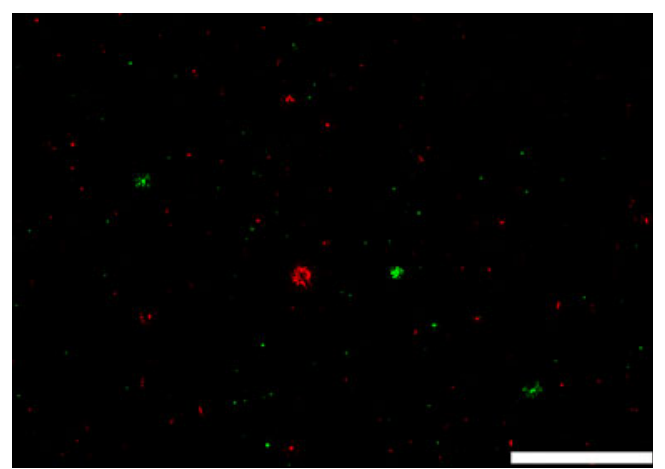

Fig. 6 Representative lectin-mediated binding of bacteria to synthetic fluorescent glycopolymers. Fluorescence microscopy of a mixture of the binding tests: P. aeruginosa with PMA-MAEMA-Texas Red $(100 \mu \mathrm{g})$ and $S$. aureus with PMA-ALAEMA-Fluorescein $(100 \mu \mathrm{g})$. Scale bar $=$ $100 \mu \mathrm{m}$ polymer), and strong associations are observed in our studies on both lectin beads and bacteria, these results suggest that these synthetic fluorescent glycopolymers could have application to many other carbohydrate-binding studies.

Some studies suggest that the length of the linker sugar may affect the binding affinities of the glycopolymers [32, 33]. In this present study, synthesis of disaccharides to be converted to lactones employed glucose as the only carbohydrate linker synthetic precursor. Hence, when the resulting disaccharide lactones were formed and reacted with AEMA, a gluconamide linker was produced. In light of these and earlier studies, our ongoing investigations include assessment of the effects of varying the length of the linker, such as ribose (five-carbon sugar) or maltose (disaccharide), to which the pendant sugars are bound.

Lastly, interactions between lectins and carbohydrates often involve more than one glycoepitope [34]. Any disaccharides or

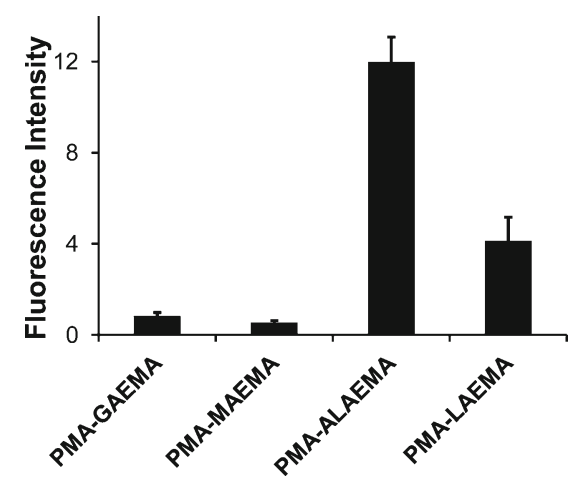

Fig. 7 S. aureus ATCC 25923 showed binding specificity towards glycopolymers containing $\beta$-galactose as the pendant sugar. Different fluorescent glycopolymers $(100 \mu \mathrm{g})$ were used in corresponding binding test, and $100 \mu \mathrm{L}$ of the final bacteria suspensions in PBS were used to measure their fluorescence intensities on the microplate reader $(\lambda \mathrm{ex} /$ $\lambda \mathrm{em}=490 / 520 \mathrm{~nm}$, slit width $=10 \mathrm{~nm}$ ) 
oligosaccharides of interest, in theory, can be conjugated onto a linear polymer following this protocol. In addition, by varying the polymer length, the ratios of glycomonomers or labeling fluorophores [33, 35], improved binding results might be achieved. Furthermore, with the combination of different fluorophores and sugars, it is now possible to accomplish the binding assays of multiple carbohydrates or crosslink different lectins all in one test. The flexibility of this method also allows for optimization of desired glycopolymer products for lectins, antibodies, or other carbohydrate-binding structures pertinent to particular glycobiology interests.

\section{Conclusions}

A class of tri-component statistical glycopolymers was successfully prepared using RAFT-based one-step polymerizations. Well-controlled reactions with good reproducibility yielded polymers with low dispersities and consistent compositions. Polymers with different degrees of polymerization and pendant sugars were synthesized. Each synthetic glycopolymer contained primary amine functional groups suitable for a variety of labels that can be attached via mild coupling chemistries, when needed. To demonstrate this, both fluorescein and Texas Red-X were used to convert the synthetic glycopolymers into excellent reporters of specific lectins immobilized on agarose beads or expressed on surface of two clinically relevant bacteria. The bacterial binding results illustrated our glycopolymers' potential for clinically relevant applications. Additional investigations are merited to optimize the binding capacities of the desired synthetic glycopolymers for specific purposes, such as by varying the polymer length, monomer ratios, linker structures, and choice and content of labels. In conclusion, the method presented here offers a relatively straightforward and dependable way to prepare heterofunctionalized linear glycopolymers for a variety of different research aims involving carbohydrate-protein specific interactions.

Acknowledgments This work was supported by the Experiment Station Chemical Laboratories at the University of Missouri.

Open Access This article is distributed under the terms of the Creative Commons Attribution License which permits any use, distribution, and reproduction in any medium, provided the original author(s) and the source are credited.

\section{References}

1. Scharfman, A., Degroote, S., Beau, J., Lamblin, G., Roussel, P., Mazurier, J.: Pseudomonas aeruginosa binds to neoglycoconjugates bearing mucin carbohydrate determinants and predominantly to sialyl-Lewis x conjugates. Glycobiology 9, 757-764 (1999)
2. Song, E.H., Manganiello, M.J., Chow, Y.H., Ghosn, B., Convertine, A.J., Stayton, P.S., Schnapp, L.M., Ratner, D.M.: In vivo targeting of alveolar macrophages via RAFT-based glycopolymers. Biomaterials 33, 6889-6897 (2012)

3. Wolfenden, M.L., Cloninger, M.J.: Multivalency in carbohydrate binding. In: Wang, B., Boons, G.-J. (eds.) Carbohydrate Recognition: Biological Problems, Methods, and Applications, pp. 349-370. Wiley, Hoboken (2011)

4. Ahmed, M., Narain, R.: The effect of molecular weight, compositions and lectin type on the properties of hyperbranched glycopolymers as non-viral gene delivery systems. Biomaterials $\mathbf{3 3}$, 3990-4001 (2012)

5. Tranter, M., Liu, Y., He, S., Gulick, J., Ren, X., Robbins, J., Jones, W.K., Reineke, T.M.: In vivo delivery of nucleic acids via glycopolymer vehicles affords therapeutic infarct size reduction in vivo. Mol. Ther. 20, 601-608 (2012)

6. Pieters, R.J.: Intervention with bacterial adhesion by multivalent carbohydrates. Med. Res. Rev. 27, 796-816 (2007)

7. Choi, S.-K., Mammen, M., Whitesides, G.M.: Generation and in situ evaluation of libraries of poly(acrylic acid) presenting sialosides as side chains as polyvalent inhibitors of influenza-mediated hemagglutination. J. Am. Chem. Soc. 119, 4103-4111 (1997)

8. Fleming, C., Maldjian, A., Da, C.D., Rullay, A.K., Haddleton, D.M., St, J.J., Penny, P., Noble, R.C., Cameron, N.R., Davis, B.G.: A carbohydrate-antioxidant hybrid polymer reduces oxidative damage in spermatozoa and enhances fertility. Nat. Chem. Biol. 1, 270-274 (2005)

9. Spain, S.G., Cameron, N.R.: A spoonful of sugar: the application of glycopolymers in therapeutics. Polym. Chem. 2, 60-68 (2011)

10. Ohlsen, K., Oelschlaeger, T.A., Hacker, J., Khan, A.S.: Carbohydrate receptors of bacterial adhesins: implications and reflections. Top. Curr. Chem. 288, 109-120 (2009)

11. Pieters, R.J.: Carbohydrate mediated bacterial adhesion. Adv. Exp. Med. Biol. 715, 227-240 (2011)

12. Ofek, I., Hasty, D.L., Doyle, R.J.: Bacterial Adhesion to Animal Cells and Tissues, New Edition. ASM Press, Herndon (2003)

13. Moad, G., Rizzardo, E., Thang, S.H.: Radical addition-fragmentation chemistry in polymer synthesis. Polymer 49, 1079-1131 (2008)

14. Spain, S.G., Gibson, M.I., Cameron, N.R.: Recent advances in the synthesis of well-defined glycopolymers. J. Polym. Sci. A Polym. Chem. 45, 2059-2072 (2007)

15. Bernard, J., Hao, X., Davis, T.P., Barner-Kowollik, C., Stenzel, M.H.: Synthesis of various glycopolymer architectures via RAFT polymerization: from block copolymers to stars. Biomacromolecules 7, 232238 (2006)

16. Bulmus, V.: RAFT polymerization mediated bioconjugation strategies. Polym. Chem. 2, 1463-1472 (2011)

17. Pearson, S., Chen, G., Stenzel, M.H.: Synthesis of glycopolymers. In: Narain, R. (ed.) Engineered Carbohydrate-Based Materials for Biomedical Applications: Polymers, Surfaces, Dendrimers, Nanoparticles, and Hydrogels, pp. 1-118. Wiley, Hoboken (2011)

18. Ting, S.R.S., Chen, G., Stenzel, M.H.: Synthesis of glycopolymers and their multivalent recognitions with lectins. Polym. Chem. 1, 1392-1412 (2010)

19. Deng, Z., Li, S., Jiang, X., Narain, R.: Well-defined galactosecontaining multi-functional copolymers and glyconanoparticles for biomolecular recognition processes. Macromolecules 42, 63936405 (2009)

20. Qin, Z., Liu, W., Li, L., Guo, L., Yao, C., Li, X.: Galactosylated N-2hydroxypropyl methacrylamide- $\beta-N$-3-guanidinopropyl methacrylamide block copolymers as hepatocyte-targeting gene carriers. Bioconjug. Chem. 22, 1503-1512 (2011)

21. Albertin, L., Wolnik, A., Ghadban, A., Dubreuil, F.: Aqueous RAFT polymerization of $\mathrm{N}$-acryloylmorpholine, synthesis of an ABA triblock glycopolymer and study of its self-association behavior. Macromol. Chem. Phys. 213, 1768-1782 (2012) 
22. Jiang, X., Ahmed, M., Deng, Z., Narain, R.: Biotinylated glycofunctionalized quantum dots: synthesis, characterization, and cytotoxicity studies. Bioconjug. Chem. 20, 994-1001 (2009)

23. Reynolds, D.D., Evans, W.L.: $\beta$-D-glucose 1,2,3,4-tetraacetate. Org. Synth. 22, 56-58 (1942)

24. Moore, S., Link, K.P.: Carbohydrate characterization. I. The oxidation of aldoses by hypoiodite in methanol. II. The identification of seven aldomonosaccharides as benzimidazole derivatives. J. Biol. Chem. 133, 293-311 (1940)

25. Noel, S., Liberelle, B., Robitaille, L., De Crescenzo, G.: Quantification of primary amine groups available for subsequent biofunctionalization of polymer surfaces. Bioconjug. Chem. 22, 1690-1699 (2011)

26. Fox, A., Morgan, S.L., Gilbart, J.: Preparation of alditol acetates and their analysis by gas chromatography (GC) and mass spectrometry (MS). In: Biermann, C.J., McGinnis, G.D. (eds.) Analysis of Carbohydrates by GLC and MS, pp. 87-170. CRC Press, Boca Raton (1989)

27. Lowe, A.B.., Wang, R.: Synthesis of controlled-structure AB diblock copolymers of 3-O-methacryloyl-1,2:3,4-di- $O$-isopropylidene-Dgalactopyranose and 2-(dimethylamino)ethyl methacrylate. Polymer 48, 2221-2230 (2007)

28. Bovin, N.V.: Polyacrylamide-based glycoconjugates as tools in glycobiology. Glycoconj. J. 15, 431-446 (1998)
29. Chen, C.P., Song, S.C., Gilboa-Garber, N., Chang, K.S.S., Wu, A.M.: Studies on the binding site of the galactose-specific agglutinin PA-IL from Pseudomonas aeruginosa. Glycobiology 8, 7-16 (1998)

30. Cioci, G., Mitchell, E.P., Gautier, C., Wimmerová, M., Sudakevitz, D., Pérez, S., Gilboa-Garber, N., Imberty, A.: Structural basis of calcium and galactose recognition by the lectin PA-IL of Pseudomonas aeruginosa. FEBS Lett. 555, 297-301 (2003)

31. Becer, C.R.: The glycopolymer code: synthesis of glycopolymers and multivalent carbohydrate-lectin interactions. Macromol. Rapid Commun. 33, 742-752 (2012)

32. Lewallen, D.M., Siler, D., Iyer, S.S.: Factors affecting protein-glycan specificity: effect of spacers and incubation time. ChemBioChem 10, 1486-1489 (2009)

33. Richards, S.J., Jones, M.W., Hunaban, M., Haddleton, D.M., Gibson, M.I.: Probing bacterial-toxin inhibition with synthetic glycopolymers prepared by tandem post-polymerization modification: role of linker length and carbohydrate density. Angew. Chem. Int. Ed. 51, 78127816 (2012)

34. Mouricout, M., Vedrine, B.: Lectin-carbohydrate interactions in bacterial pathogenesis. In: Caron, M., Seve, A.-P. (eds.) Lectins and Pathology, pp. 157-171. Harwood Academic Publishers, Newark (2000)

35. Bovin, N.V.: Neoglycoconjugates: trade and art. Biochem. Soc. Symp. 69, 143-160 (2002) 